\title{
A Framework for Open Civic Design: Integrating Public Participation, Crowdsourcing, and Design Thinking
}

\author{
BRANDON REYNANTE, Stanford University \\ STEVEN P. DOW, University of California San Diego \\ NARGES MAHYAR, University of Massachusetts Amherst
}

\begin{abstract}
$\overline{\text { Civic problems are often too complex to solve through traditional top-down strategies. Various governments and civic initia- }}$ tives have explored more community-driven strategies where citizens get involved with defining problems and innovating solutions. While certain people may feel more empowered, the public at large often does not have accessible, flexible, and meaningful ways to engage. Prior theoretical frameworks for public participation typically offer a one-size-fits-all model based on face-to-face engagement and fail to recognize the barriers faced by even the most engaged citizens. In this article, we explore a vision for open civic design where we integrate theoretical frameworks from public engagement, crowdsourcing, and design thinking to consider the role technology can play in lowering barriers to large-scale participation, scaffolding problem-solving activities, and providing flexible options that cater to individuals' skills, availability, and interests. We describe our novel theoretical framework and analyze the key goals associated with this vision: (1) to promote inclusive and sustained participation in civics; (2) to facilitate effective management of large-scale participation; and (3) to provide a structured process for achieving effective solutions. We present case studies of existing civic design initiatives and discuss challenges, limitations, and future work related to operationalizing, implementing, and testing this framework.
\end{abstract}

CCS Concepts: • Human-centered computing $\rightarrow$ Collaborative and social computing; $\bullet$ Applied computing $\rightarrow$ Computers in other domains; Computing in government;

Additional Key Words and Phrases: Civic design, digital civics, public participation, crowdsourcing, design thinking, conceptual framework

\section{ACM Reference format:}

Brandon Reynante, Steven P. Dow, and Narges Mahyar. 2021. A Framework for Open Civic Design: Integrating Public Participation, Crowdsourcing, and Design Thinking. Digit. Gov.: Res. Pract. 2, 4, Article 31 (December 2021), 22 pages.

https://doi.org/10.1145/3487607

\section{INTRODUCTION}

Many municipalities face "wicked" problems too complex and interconnected to address through conventional top-down strategies where a small group of experts and elected officials create and enact proposals [92]. Civic problems can be wicked for several reasons. First, many civic problems involve numerous stakeholders who

The National Science Foundation provided funding for this research under grant \#1122206 and \#2009003.

Authors' addresses: B. Reynante, Stanford University, 450 Serra Mall, Stanford, CA 94305; email: reynante@stanford.edu; S. P. Dow, University of California San Diego, 9500 Gilman Dr, La Jolla, CA 92093; email: spdow@ucsd.edu; N. Mahyar, University of Massachusetts Amherst, 140 Governors Dr, Amherst, MA 01003; email: nmahyar@cs.umass.edu.

Permission to make digital or hard copies of all or part of this work for personal or classroom use is granted without fee provided that copies are not made or distributed for profit or commercial advantage and that copies bear this notice and the full citation on the first page. Copyrights for components of this work owned by others than ACM must be honored. Abstracting with credit is permitted. To copy otherwise, or republish, to post on servers or to redistribute to lists, requires prior specific permission and/or a fee. Request permissions from permissions@acm.org.

(c) 2021 Association for Computing Machinery.

2639-0175/2021/12-ART31 \$15.00

https://doi.org/10.1145/3487607

Digital Government: Research and Practice, Vol. 2, No. 4, Article 31. Publication date: December 2021. 
hold differing and often conflicting perspectives. For example, many urban design projects need to consider the perspectives of residents, domain experts (e.g., public planners, architects, civil engineers), nonprofit and community-based organizations, businesses, and government officials [8, 89, 92]. Second, they involve various social regulations and laws that may impose contradictory constraints that force difficult trade-offs [89, 92]. Third, they involve enormous volumes of multifaceted and unstructured data in diverse formats (e.g., text, images, geographic information) [78,112]. Given the need for contextual knowledge of problems, broad exploration of alternative solutions, and agreement among stakeholders [8], many government agencies have started to explore more community-driven approaches to civic issues.

Citizens (i.e., residents without regard to legal status) have the potential to provide local knowledge and perspectives on civic issues $[2,16,112]$, to synthesize data [26, 60], and to innovate new solutions $[16,50,77]$. A collective approach can lead to more accurate and equitable civic decision-making [64]. Failing to leverage the vast knowledge and creativity of citizens constitutes not only a missed opportunity, but can also lead to feelings of neglect, distrust, and cynicism toward government [40]. Elected officials who apply a top-down approach and drive their own agendas run the risk of having the public reject any proposed changes [10, 44]. Thus, involving citizens is crucial for improving the morality and legitimacy of civic decision-making [41, 47]. Furthermore, outsourcing the innovation process may also reduce the financial and labor costs of government agencies $[22,49]$.

Community-driven approaches often face organizational challenges that reduce their potential impact on public decisions. Initiatives that emphasize public engagement typically struggle to achieve consensus, suffer from poor organization and facilitation, and fail to manage the scale needed to get input from all stakeholders [71]. Traditional co-located approaches to public participation-such as town hall meetings-often give a soapbox to the most vocal attendees and are limited in scale and inclusiveness due to costs and constraints associated with participation (e.g., time, transportation, childcare) [19, 41, 52, 54, 98]. Thus, people with higher education, income, socioeconomic status, and intrinsic interest in civic duty are the ones most likely to be civically engaged $[30,111]$. Most citizens simply do not have the capacity to get involved at the level necessary to have influence. Attempts to scale up and diversify civic engagement through digital technologies tend to involve citizens in a relatively passive role-as either "consumers" [32, 49] or a network of "sensors" [43]-and do not involve them as partners in the process of designing, developing, and implementing solutions [77].

The complex nature of civic problems, the need for more democratic governance processes, and the increasing prevalence of digital communication devices has led us to re-envision digital government as a more inclusive participatory process informed by theoretical frameworks from three diverse bodies of literature: public participation, crowdsourcing, and design thinking. Key frameworks for public participation, such as Fung's Democracy Cube [40], aim to create a variety of opportunities for citizens to shape civic decision-making, but they primarily consider traditional forms of face-to-face participation that are inherently limited in their ability to effectively scale to account for more stakeholders. Frameworks from crowdsourcing, such as Kittur et al.'s Future of Crowd Work [61], suggest ways to scale up and diversify participation by using digital technologies to lower costs, to delineate and scope tasks, to incentivize work, and to assure consistency and reliability. While the prior literature reports on numerous initiatives that leverage approaches from crowdsourcing for civics [49,87], they often constrain involvement to a single type of activity (e.g., reporting infrastructure breakdowns [114]), without recognizing that most civic solutions emerge through a lengthy and iterative process. Some scholars have called on governments to employ "design thinking"-such as Stanford's d.school framework [102] -as an organizing principle for civics because it provides a systematic process for tackling the complexity of wicked problems by emphasizing broad exploration of problem-solution spaces and iterative prototyping and testing [89]. While these existing frameworks each provide key conceptual directions for improving civic problem solving, they are limited and/or outdated. The digital government community lacks a coherent theoretical framework for engaging and managing participation at scale in creative problem-solving processes while providing a variety of participation options that vary based on a particular citizen's availability and interest.

Digital Government: Research and Practice, Vol. 2, No. 4, Article 31. Publication date: December 2021. 
This article contributes a novel theoretical framework for open civic design. This article focuses on the context of the United States, so the concepts for the framework are strongly rooted in democracy and may not translate to other forms of government. The ability to implement and adapt the framework depends on cultural and political factors that affect a society's ability to freely participate, either directly or through elected representatives. We first present an extensive literature review to outline the promises and limitations of existing theoretical frameworks for public participation, crowdsourcing, and design thinking. Next, we describe our proposed Open Civic Design framework and outline three key goals: (1) to promote broad participation in civics, (2) to manage large-scale participation, and (3) to provide a structured process for achieving solutions that work better for a community. The Open Civic Design framework integrates and extends existing theoretical frameworks to leverage their affordances and mitigate their limitations with respect to these key goals. We draw upon public participation frameworks to emphasize a variety of engagement options that give citizens the flexibility to choose their own level, mode, and duration of participation. We draw upon crowdsourcing frameworks to diversify and organize participation at scale using digital tools and technologies. We also integrate design thinking frameworks to structure problem solving as a human-centered, iterative, multi-phase process. We then present a few case studies of existing civic design initiatives examined hypothetically using the framework to demonstrate its validity and utility. Finally, we discuss considerations, challenges, and potential future research directions related to operationalizing, implementing, and testing the framework.

\section{RELATED WORK}

Civic design seeks to apply design approaches to the civic domain to streamline existing government processes and create new modes of political organizing and action [32]. Digital government provides one avenue for supporting civic design by focusing on the creation of digital tools and technologies that have the potential to facilitate civic engagement by lowering participation costs and supporting interactions among diverse individuals [19]. One prominent model of digital government has focused on the use of information and communication technologies (ICTs) to support existing government operations, such as providing public information and services to citizens $[94,110]$. Some scholars critique these initiatives as being transactional-that is, based on a free-market model of citizens as consumers, government as producers, and digital technology as a means of reducing transaction costs $[32,108]$. In contrast, the emerging paradigm of digital civics emphasizes the design of new technologies that support relational-as opposed to transactional-interactions, where citizens are agents of democracy in dialogue with institutions that can actualize public will $[91,108]$.

Advances in digital technology have opened new pathways for networked communication among many stakeholders. While the digital divide still needs to be addressed, advocates of digital civics see an opportunity to reach many more people than ever before. However, we need to think carefully about how best to manage the potential scale of participation, and technology alone is not a silver bullet. We also need careful consideration of issues like motivation, power structures, time commitment, and attention management. Given the confluence of diverse insights and wisdom from multiple domains, a new integrative framework could help civic leaders, scholars, and government officials work more effectively with technology to enable large-scale participation in civic design. This article attempts to advance a coherent theoretical framework for supporting relational civic engagement and systematic problem solving at scale. In this section, we describe existing theoretical frameworks in three key domains-public participation, crowdsourcing, and design thinking-to motivate the need for a new, integrative framework. Figure 1 is a Venn diagram that illustrates the intersection of these three diverse domains of study that converge as part of the Open Civic Design framework.

\subsection{Public Participation Frameworks}

Public participation activities aim to inform the public about policy issues, improve government decisions by increasing the flow of information from citizens to decision makers, create opportunities for citizens to shape and

Digital Government: Research and Practice, Vol. 2, No. 4, Article 31. Publication date: December 2021. 


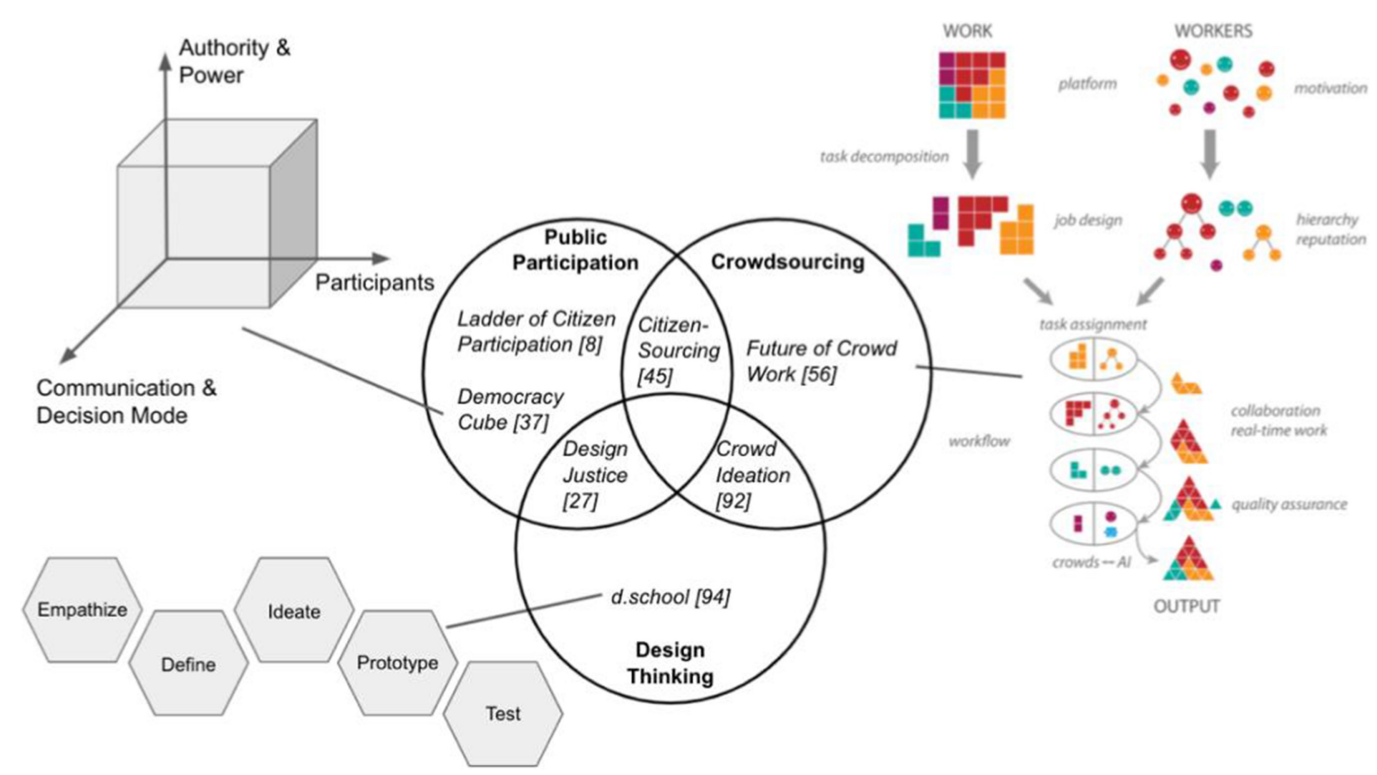

Fig. 1. The Open Civic Design framework explores the intersection of existing theoretical frameworks from public participation, crowdsourcing, and design thinking. (Future of Crowd Work image courtesy of ACM [56].).

determine policy, and legitimize government decisions by ensuring the voices of those impacted by government policy have been considered [105]. Features of successful public participation initiatives include the realistic expectation of influence (i.e., a link to decision makers) and a representative process that brings key stakeholders together [71].

One of the more influential public participation frameworks is Arnstein's Ladder of Citizen Participation, which characterizes the level of citizen participation based on the amount of power given to citizens [9]. The bottom rungs of Arnstein's Ladder indicate non-participation, the middle rungs indicate tokenism, and the top rungs indicate citizen power (including partnership). Arnstein's Ladder was developed in the 1960s to analyze the participation of marginalized groups in U.S. social programs, such as urban renewal, and it has been applied widely in civic contexts. For example, the framework has been used to analyze citizen participation in online U.S. government collaboration platforms [72]. While Arnstein's Ladder strives to give the public more control, Fung [40] argues that not everyone will have the capacity or desire to be involved at a partnership level. Fung's Democracy Cube [40] builds on Arnstein's ladder by emphasizing a variety of participation options at various levels of involvement and by considering participation along three dimensions: (1) scope of participation (i.e., who participates), from more exclusive to more inclusive; (2) mode of communication and decision-making, from least intense (e.g., spectator) to most intense (e.g., deliberator); and (3) extent of authority (i.e., how discussions are linked with policy or action). Empirical research supports the argument that providing multiple forms of public participation can lead to more successful civic processes and outcomes [24].

These frameworks for public participation typically work under the assumption that people will engage in person; they do not adequately account for new opportunities and scales that may be achieved through digital technologies. Recent efforts to extend these frameworks into the digital domain has led to the development of technology-enabled participatory platforms. Yet, studies of such platforms have found that most do not provide citizens opportunities to participate at the upper rungs of Arnstein's Ladder, few offered both online and offline participation modes, and none offered more than a single level and type of participation [31,37]. Government agencies often struggle to adopt digital participatory platforms due to organizational challenges associated with 
citizen participation [38]. Furthermore, it is not entirely clear what exactly constitutes citizen participation. Theories from crowdsourcing could help provide rigor around operationalizing and managing participation from many people with different capacities, skills, and roles.

\subsection{Crowdsourcing Frameworks}

In recent years, there has been increasing interest in designing technologies that can support democratic civic participation [11,14]. Digital technologies have the potential to scale up and diversify civic engagement by lowering participation costs and supporting interactions among diverse individuals [12, 19, 79]. Some researchers further argue that technology should go beyond open calls for citizen participation to also target and match people to the right opportunities to participate [90]. One particularly promising model for scaling up participation is crowdsourcing, where initiatives can harness the collective intelligence of large numbers of distributed individuals to complete small tasks $[15,104]$. Engaging non-experts in problem-solving has been shown, in some instances, to result in superior and more cost-effective solutions [50,63]. Crowdsourcing potentially taps into the wisdom of crowds, where aggregating input from many people often outperforms a single expert [104].

A prominent crowdsourcing framework is Kittur et al.'s Future of Crowd Work [61], which proposes several key features for effective crowd work platforms. Successful crowdsourcing platforms divide complex tasks into micro-tasks: coherent sub-dividable tasks that can be easily decomposed, partitioned, assigned to independent workers, and solved rapidly. Kittur et al.'s framework argues that workers must be properly selected (e.g., based on skills), organized (e.g., through hierarchy), and motivated (e.g., through incentives). They envision task decomposition and multi-stage workflows that account for dependencies between subtasks and that allow for workers to collaborate in both synchronous and asynchronous modes [63]. Tasks can be assigned based on interests and skills, which can lead to higher participant satisfaction and performance [61]. To support these activities, Artificial Intelligence (AI) systems could guide, or be guided by, crowds. Quality control measures are required to assure consistency and reliability of outputs [113]. Crowdsourcing in the civic domain-referred to as citizen-sourcing $[49,87]$-has been used to enable citizens to participate in urban planning projects [16, 17, 84], contribute ideas and opinions for improving public service delivery [82], and inform policy-making processes $[2,3]$.

These crowdsourcing frameworks also have limitations. First, many crowdsourcing initiatives conceptualize participants as either sensors [2,3], task completers/workers [60], or ideators (e.g., crowd ideation [100]), but rarely as true collaborators [49, 87]. In citizen-sourcing, for example, citizens often provide information to government officials who retain all decision-making power. This is a form of participatory democracy, rather than direct democracy, where citizens would directly decide on policy [1]. Second, participation is typically limited to a single level, mode (i.e., online rather than face-to-face), and design phase [72, 93]. Third, technological innovations cannot achieve just and democratic outcomes on their own [96]. Civic technologies alone cannot establish trusted relationships between the public and government [27, 46]. These technologies also amplify issues related to digital access (the so-called "digital divide") [16, 98], and may only attract individuals who already engage in traditional civic processes and fail to engage others who are often left out [21,57]. Attention must also be paid to the organizational structures and processes that motivate and facilitate collaborative problem-solving among citizens and government agencies [86]. While many civic initiatives leverage crowdsourcing, they often assume a straightforward, linear workflow and fail to recognize that effective civic solutions are more likely to emerge through an iterative process, such as design thinking.

\subsection{Design Thinking Frameworks}

"Design Thinking" is a term that encompasses both the mindsets of design practitioners and their systematic, human-centered, creative problem-solving process [88]. Simon described design as a way of thinking in 1969, defining it as the science of creating and maintaining the artificial world by solving determinate problems

Digital Government: Research and Practice, Vol. 2, No. 4, Article 31. Publication date: December 2021. 
(i.e., those with definite requirements and conditions) [101]. Later, other design scholars argued that many problems addressed by designers are "wicked problems"-too complex, messy, and interdependent on social factors to be handled through rational scientific approaches [20,92]. In this view, design thinking reflects the intuitive processes of skilled practitioners [95], described by Cross as "designerly" ways of knowing [29]. Starting in the 1990's, the design firm IDEO formalized and popularized a multi-phase design thinking process in the context of product design [18].

One widely used design thinking framework, from Stanford's d.school [102], defines a five-phase process: (1) "Empathize" with people-through observation and other methods-to collect data about their needs, behaviors, and motivations; (2) "Define" the design problem by synthesizing the collected data; (3) "Ideate" a broad range of potential solution ideas; (4) "Prototype" artifacts that embody the best ideas; and (5) "Test" prototypes to solicit feedback. Each step of the process, as well as the entire process itself, can be iterative. Solutions to complex civic problems might be more effective if they are developed through systematic and iterative processes [89].

Design thinking frameworks typically assume that the process will be driven by professional designers. This can be problematic in the civic domain where it may reinforce existing power inequities and undermine the perceived legitimacy of the process [28]. Participatory and community-driven design methods have emerged in the past few decades or so to explore how to open up the design process by recognizing and leveraging the local knowledge of community members and ensuring they have fair and meaningful participation in design decisions [28, 67, 97]. For example, Costanza-Chock's Design fustice framework [28] visualizes how community participation unfolds across the life of a design project in the form of a two-axis chart, where the horizontal axis represents the phase of the design process, and the vertical axis represents the degree of community member participation (inspired by Arnstein's Ladder). One limitation of participatory design approaches is that they have typically involved face-to-face interaction among stakeholders, which has restricted participation to relatively small groups [43]. This article seeks to expand upon the Design fustice framework by considering how crowdsourcing methods can enable initiatives to handle larger scale participation by leveraging technology to facilitate online remote participation and methods from crowdsourcing to manage dynamic task decomposition and allocation.

\section{A FRAMEWORK FOR OPEN CIVIC DESIGN}

This article offers a novel theoretical framework for Open Civic Design that envisions an iterative process for large-scale public participation by scaffolding problem-solving activities and providing flexible opportunities for citizens to get involved. The Open Civic Design framework has three goals: (1) to promote inclusive and sustained participation in civics; (2) to facilitate effective management of large-scale participation; and (3) to provide a structured process for achieving effective solutions. To address these goals, we integrate and extend existing frameworks from public participation, crowdsourcing, and design thinking to leverage their affordances and overcome their limitations as outlined in Related Work. The Open Civic Design framework is visualized in Figure 2 , with the vertical axis indicating the degree and scale of citizen involvement, the horizontal axis indicating progress of an initiative over time, and the inner region indicating goal decomposition, activity allocation, and output validation and synthesis throughout each phase of a civic design process.

The Open Civic Design framework draws from the Stanford d.school model [102] to illustrate an iterative process with multiple phases. Each phase will generally have a particular set of goals that must be accomplished before moving onto the next phase. We do not propose any specific phases as we recognize that there may be many ways to structure a design process. Potential civic design solutions include physical and digital artifacts, services, as well as policies, all of which influence human behavior in different ways. Policymaking processes involve agenda setting, analysis, policy creation, acceptance, implementation, and monitoring and evaluation $[51,76]$. The first phase of any civic design initiative will likely involve the organizers engaging in the task of "infrastructuring": the ongoing process of identifying, creating, and supporting socio-technical resources that support civic activities $[13,69,103,109]$. Two key components of the support infrastructure needed for Open

Digital Government: Research and Practice, Vol. 2, No. 4, Article 31. Publication date: December 2021. 


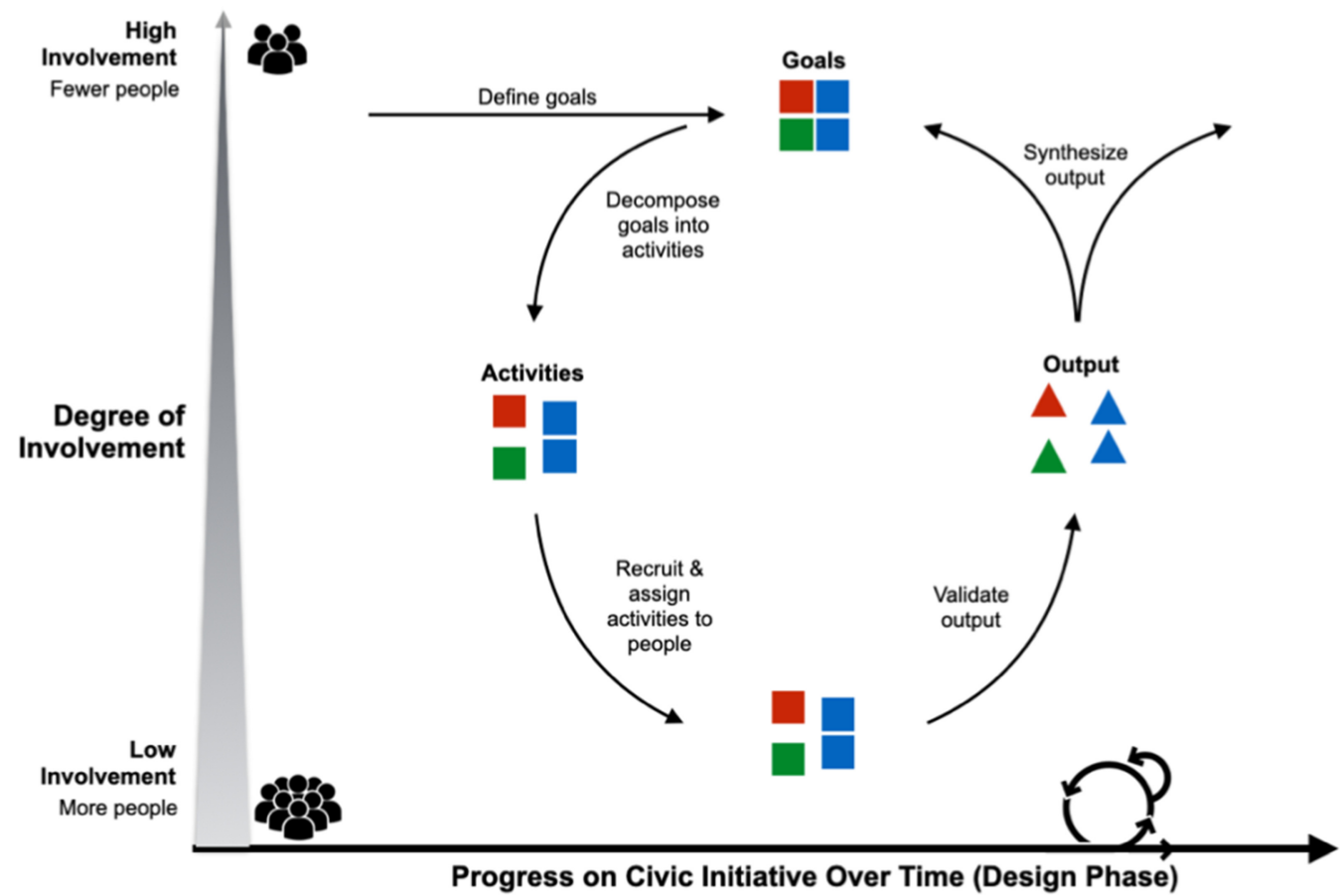

Fig. 2. A framework for Open Civic Design. The vertical axis indicates degree and scale of citizen involvement; the horizontal axis indicates progress along an iterative, multi-phase design process; and the inner diagram illustrates decomposition of goals, assignment of activities to citizens, and validation and synthesis of outputs during each phase. A key goal is to allow citizens to engage at different degrees of involvement as initiatives progress through different phases.

Civic Design initiatives are an innovation ecosystem and an innovation platform [86]. An innovation ecosystem is the organizational structure that facilitates collaborative problem-solving among stakeholders, which includes shared expectations regarding stakeholders' roles, guidelines for participants' contributions to be coordinated and integrated, and policies for decision-making. An innovation platform is the physical and/or virtual venue for problem solving, which partitions the problem-solving process to make it more manageable, brings together relevant resources, and provides communication infrastructure and protocols to facilitate different types of interactions among participants. As a project evolves, its goals and associated activities will change. The composition of active participants will also vary dynamically as some citizens leave and new citizens join according to their availability. Each phase, as well as the entire process itself, can be iterative to ensure that any unmet or evolving goals are achieved.

The Open Civic Design framework also builds on Fung's Democracy Cube framework [40] to emphasize inclusiveness and flexible participation options (i.e., "points of entry") that allow citizens to choose their own time, level, mode, and duration of involvement. While the Democracy Cube considers the scale and intensity of participation as separate dimensions, we combine them into a single dimension to illustrate a perceived inverse relationship: fewer people will take up high-involvement roles and more people will engage in low-involvement roles. The Open Civic Design framework thus allows for multiple different types of simultaneous participation in a so-called "community of practice," where individuals can be core, active, occasional, peripheral, or transactional participants [66]. Modes of participation might include face-to-face (e.g., public workshops), digital technologies (e.g., online platforms, mobile apps), and in-situ technologies (e.g., kiosks, public displays). Providing both in-person and online options will likely enable the initiative to reach more citizens. One consideration is that the 
Table 1. Phases and Types of Activities for a Hypothetical Open Civic Design Process

\begin{tabular}{|l|l|l|l|}
\hline Design Phase & \multicolumn{1}{|c|}{$\begin{array}{c}\text { High-Involvement } \\
\text { Activities }\end{array}$} & \multicolumn{1}{|c|}{$\begin{array}{c}\text { Medium-Involvement } \\
\text { Activities }\end{array}$} & \multicolumn{1}{|c|}{$\begin{array}{c}\text { Low-Involvement } \\
\text { Activities }\end{array}$} \\
\hline Empathize & $\begin{array}{l}\text { Rally community around } \\
\text { important problem }\end{array}$ & $\begin{array}{l}\text { Review and synthesize } \\
\text { issues }\end{array}$ & $\begin{array}{l}\text { Identify and report local } \\
\text { issues }\end{array}$ \\
\hline Define & $\begin{array}{l}\text { Frame key design } \\
\text { questions }\end{array}$ & $\begin{array}{l}\text { Analyze collected data } \\
\text { about the issues }\end{array}$ & $\begin{array}{l}\text { Vote on proposed design } \\
\text { briefs }\end{array}$ \\
\hline Ideate & $\begin{array}{l}\text { Organize teams for } \\
\text { brainstorming }\end{array}$ & $\begin{array}{l}\text { Synthesize and combine } \\
\text { ideas }\end{array}$ & $\begin{array}{l}\text { Submit, discuss, and } \\
\text { vote on ideas }\end{array}$ \\
\hline $\begin{array}{l}\text { Prototype and } \\
\text { Test }\end{array}$ & $\begin{array}{l}\text { Create prototypes and } \\
\text { testing opportunities }\end{array}$ & $\begin{array}{l}\text { Analyze and synthesize } \\
\text { collected data from testing }\end{array}$ & $\begin{array}{l}\text { Compare prototypes and } \\
\text { provide feedback }\end{array}$ \\
\hline
\end{tabular}

Open Civic Design framework still requires some high-involvement citizens at all phases of the design process who can provide "institutional memory" and set goals and direction, such as volunteer community leaders.

To tie together the evolving goals of a civic initiative with the need to support different degrees of involvement at large scales of participation, we draw upon Kittur et al.'s Future of Crowd Work framework [61] to propose the use of crowdsourcing techniques to support and manage a whole spectrum of engagement opportunities. The Open Civic Design framework illustrates how goals translate into specific concrete activities that could be performed by citizens with varying levels of involvement. Technologies to support this organizational perspective could help civic initiatives define project goals at each phase, decompose goals into activities, manage workflows to account for task interdependencies, assign micro-activities to citizens based on their skills, interests, and availabilities, provide incentives for participation, and guide the validation and synthesis of outputs. The increased scale of participation provided by crowdsourcing would potentially allow for a richer, broader, and more diverse understanding of the problem space, a higher quality and diversity of ideas, and increased public buy-in by providing opportunities for more citizens to be involved in analyzing, critiquing, and debating those ideas.

The Open Civic Design framework suggests there should be a range of high-, medium-, and low-involvement activities throughout the civic problem-solving process, and that these activities adapt to the goals of each project phase. For example, activities for each phase of a hypothetical civic design process are listed in Table 1.

The Open Civic Design framework could be used for both prescriptive (i.e., planning) and descriptive (i.e., evaluation) purposes across a range of civic design projects, both large (e.g., a public transit system) and small (e.g., a playground). It can also support the design of technologies to support civic design initiatives. As such, the framework is oriented towards a diverse range of stakeholders including citizens, domain experts (e.g., transportation engineers, public planners), nonprofit and community-based organizations, businesses, civic technology designers and researchers, and government officials. Initiatives using the framework could be spearheaded by governments and/or community leaders. Contextual issues that should be considered when adapting the framework include existing physical and digital infrastructure, local citizen needs and capacities, governance structures, and funding opportunities. The framework is meant to augment, rather than replace, traditional modes of engagement. However, the framework does not guarantee that initiatives will or should scale up. We offer the framework to help civic initiatives think about how to manage larger scales of participation, but it does not prescribe scale as a catch-all solution. In some cases, large-scale participation may take more effort and cause more conflict than a particular initiative requires.

To make the framework more concrete, we describe the experience of a hypothetical citizen, Jane, who lives in a mid-sized U.S. city. She hears about an upcoming climate action initiative to address the increasing frequency and intensity of flash floods in her community. The initiative is being spearheaded by a local nonprofit organization 


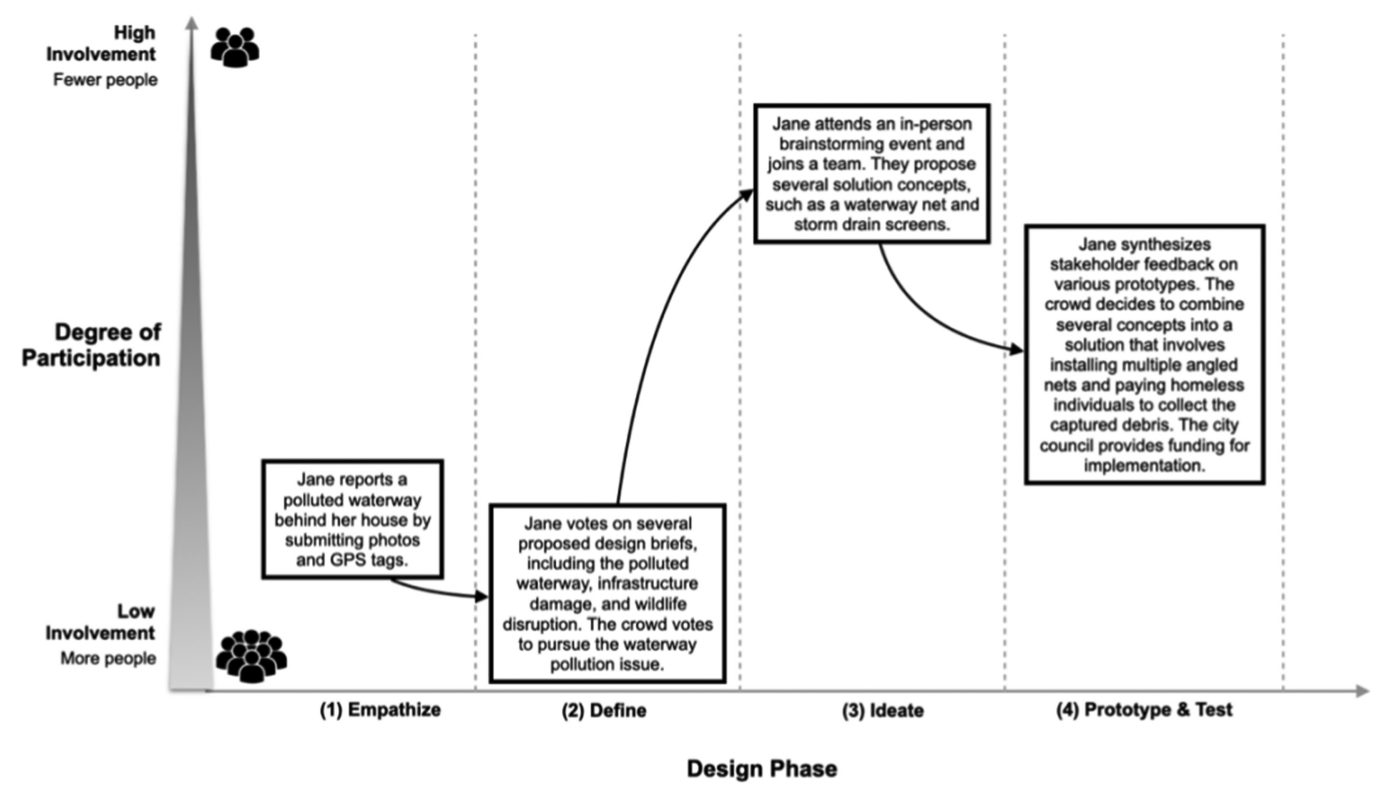

Fig. 3. Example path of a single citizen, Jane, throughout a hypothetical Open Civic Design initiative that aims to address the increasing frequency and intensity of flash floods in her community.

with a mission to protect local waterways and natural habitats, in collaboration with members of the City Council. Jane's path of involvement throughout the initiative is illustrated using the framework in Figure 3.

In the Empathize phase, Jane only has time to get involved at a low level due to childcare constraints, so she decides to report a local problem she has been concerned about for the last few years. During heavy rains, a stormwater channel by her house that flows into a nearby creek becomes inundated with trash. This garbage flows into the creek and impacts the surrounding natural habitats and recreation spaces. Jane logs onto a website through her phone and completes a few micro-activities such as submitting photos of the issue with corresponding GPS locations. She again has limited time during the Define phase, so the platform directs her to vote on proposed design briefs created by other high-involvement participants to help narrow down the problem space. She learns that other citizens also reported issues such as groundwater contamination, disruption of wildlife, and damage to infrastructure. Jane votes to pursue the waterway trash issue, and this issue ultimately receives the most votes from the other initiative participants. In the Ideate phase, Jane's children are in school, so she gets more highly involved by attending an in-person brainstorming event and joining an ad-hoc team. Her team proposes several solution concepts, including a giant net that spans the waterway and screens that cover sidewalk storm drains. In the Prototype \& Test phase, Jane wants to be moderately involved, so the initiative assigns her some mid-level organizational tasks like synthesizing stakeholder feedback on prototypes of various solution concepts. The work to synthesize input from various stakeholders helps the initiative leaders to combine several concepts into a solution proposal where multiple nets would span portions of the channel to capture trash and homeless individuals would be paid by the city to collect it. In part due to citizens' widespread buy-in to the process and proposed solutions, the City Council provides funding for implementation of this proposal.

\section{CASE STUDIES}

To illustrate the potential of open civic design, we present several civic-design case studies and explore how the Open Civic Design framework could have hypothetically enhanced the initiatives. We first apply the framework in a descriptive manner to explore how each initiative supports the three key goals of the framework. We then

Digital Government: Research and Practice, Vol. 2, No. 4, Article 31. Publication date: December 2021. 
apply the framework in a prescriptive manner to suggest ways to extend and improve upon each initiative such that it better meets its original goals as well as the key goals of the framework. These cases were chosen because they are representative of many other civic design initiatives and because they each incorporate distinct, yet limited, aspects of the framework.

\subsection{Case Study \#1: CommunityCrit}

The first initiative we examine is CommunityCrit, an online civic engagement tool that allows community members to share and critique proposed solution ideas [77]. CommunityCrit was evaluated through a case study to redesign a major street intersection in downtown San Diego, CA in 2018, as a more pedestrian-friendly and sustainable green space in partnership with a local planning group. Many local community members described difficulties attending in-person meetings and having their voices heard. The CommunityCrit platform utilized online micro-activities to engage citizens at their convenience and gather meaningful input in a short amount of time (about 10 minutes per participant). Over the four-week deployment, 39 people-including residents, planners, designers, and business owners - made a total of 352 contributions that were considered comparable or better to what could have been elicited through face-to-face meetings. Community members, particularly those not previously involved in civic processes, stated that it was a convenient way to add their voice.

CommunityCrit already supported a couple of the Open Civic Design framework's key goals by offering a variety of flexible participation options (e.g., different activities, in person or online) and leveraging crowdsourcing techniques to manage participation (e.g., through a micro-task workflow). Hypothetically, the initiative could have been further enhanced by the Open Civic Design framework by expanding CommunityCrit to include mid-level involvement activities, such as sensemaking and synthesis of the shorter contributions by others. Furthermore, the framework suggests that CommunityCrit could be expanded to support more stages of the civic problem-solving process. The initiative could have gone beyond simply ideating and commenting on a known problem. The Open Civic Design framework suggests that more people could get involved in the early stages of understanding and defining problems, as well as in the later stages of prototyping and testing solutions. Incorporating additional phases does not mean the framework prescribes a simple linear process; initiatives often evolve, stall, and pivot in various ways over time. To mitigate these challenges, civic platforms and initiatives that leverage the Open Civic Design framework must be sufficiently flexible to adapt to the situation, allow participants to see a history of past activities and decisions, and empower leaders to take on high-involvement roles to oversee and manage community involvement throughout a design process.

\subsection{Case Study \#2: Malmo Living Labs}

The second initiative we describe is Malmo Living Labs, a civic design initiative in Sweden, founded in 2007, that has carried out more than 30 design experiments with 300 participants in partnership with 18 companies and organizations [13]. Facilitators at Malmo Living Labs engaged in infrastructuring to support participantsparticularly groups traditionally marginalized in civic processes-as active co-creators rather than participatory end users. This approach fostered long-term relationships with diverse stakeholders and enabled issues and ideas to evolve from bottom-up collaborations.

Looking at this initiative through the lens of the Open Civic Design framework highlights how Malmo Living Labs supports widespread participation by enabling citizens to choose activities based on their skills and interests. The initiative also engaged citizens throughout an entire multi-phase design process, including defining problems, ideating solutions, and creating prototypes. Malmo Living Labs sought to democratize innovation by engaging a diverse range of participants, particularly those from marginalized groups. While it was successful at this goal on a small scale, Malmo Living Labs was limited to interactions in physical spaces and roles that all required a significant degree of involvement. Focusing only on in-person, high-bandwidth activities can limit the scale and inclusiveness of civic initiatives. The Open Civic Design framework would suggest offering a variety

Digital Government: Research and Practice, Vol. 2, No. 4, Article 31. Publication date: December 2021. 
of options for both the involvement level and participation mode (i.e., in-person and online). For example, the Malmo Living Labs facilitators could have leveraged online and mobile technologies to open ways for a broader portion of the local population to make small but useful contributions, such as voting on design ideas proposed by the citizen co-creators.

\subsection{Case Study \#3: MIT Climate Co-Lab}

The final case study examines the MIT Climate Co-Lab, an online crowdsourcing platform that has engaged thousands of people in creating, analyzing, and selecting solutions to climate change since 2009 [35, 53]. The platform facilitates solution exploration by allowing anyone around the world to submit a proposal consisting of climate simulations, graphics, and text descriptions. Each proposal has its own structured online discussion forum in which users can comment on and debate the details. The platform facilitates electronic voting and rating to select proposals for funding. In addition to these low-level activities for citizens, the platform includes roles for advisors (i.e., experienced engineers, climate scientists, etc.) to write briefs to frame contests, to provide input on proposals, and to reach out to key stakeholders to implement contest-winning proposals. Climate CoLab also includes volunteer roles for moderators who are responsible for monitoring the site, deleting spam and inflammatory material, and facilitating community interaction and content creation. Activity has been driven by a series of annual contests with a multi-round design process in which users submit plans, expert judges select viable proposals, and the community votes.

The Climate Co-Lab perhaps comes closest to reaching the ideal of a multi-stage, large-scale, multi-role design process, and its goals align with those of the Open Civic Design framework. The initiative (1) offers a wide variety of roles and participation options, (2) utilizes crowdsourcing techniques to manage large-scale participation, and (3) provides structured participant engagement throughout a multi-phase design process. The Open Civic Design framework could provide further insight in support of these goals. For instance, the management of task decomposition, allocation, and synthesis could potentially be handled in a more systematic manner. Advances in crowdsourcing mechanisms could enable the decomposition and matching of activities to appropriate participants based on their skills, interest, and availability. This could potentially lead to more open, efficient, and effective problem-solving processes and outcomes.

\subsection{Practical Application and Implementation}

The application of the Open Civic Design framework for descriptive and prescriptive purposes as performed in this section illustrates how the framework might be used in practice. The analysis of existing initiatives provides theoretical support for the validity and utility of the framework. We showed how each initiative incorporated some dimensions of the framework already, but we also discussed how they could be enhanced by the Open Civic Design framework. The Open Civic Design framework suggests comprehensive end-to-end support for the civic design process, which can be achieved by expanding current platforms or integrating tools to reach the framework's vision. To illustrate how such integration can facilitate a variety of hybrid participation options (i.e., online and in-person) at different stages of a structured civic design process, we map three existing platforms (CommunityCrit, CommunityClick, and CommunityPulse) onto the Open Civic Design framework and offer a hypothetical use case (see Figure 4).

As described in Section 4.1, CommunityCrit is an online civic engagement tool that allows community members to share and critique proposed solution ideas [77]. While online platforms broaden the cast and help with diversifying participation and increasing scale, they do not provide mechanisms for capturing attendees' feedback in face-to-face meetings. This is a missed opportunity for gathering feedback from an engaged portion of the public who, despite numerous barriers, attend face-to-face public meetings.

The CommunityClick [56] platform tries to address this issue and in particular increase inclusive participation at in-person community consultation meetings. CommunityClick allows attendees to use modified iClickers to provide real-time, silent, anonymous feedback, and it provides organizers with visual analytics tools to

Digital Government: Research and Practice, Vol. 2, No. 4, Article 31. Publication date: December 2021. 


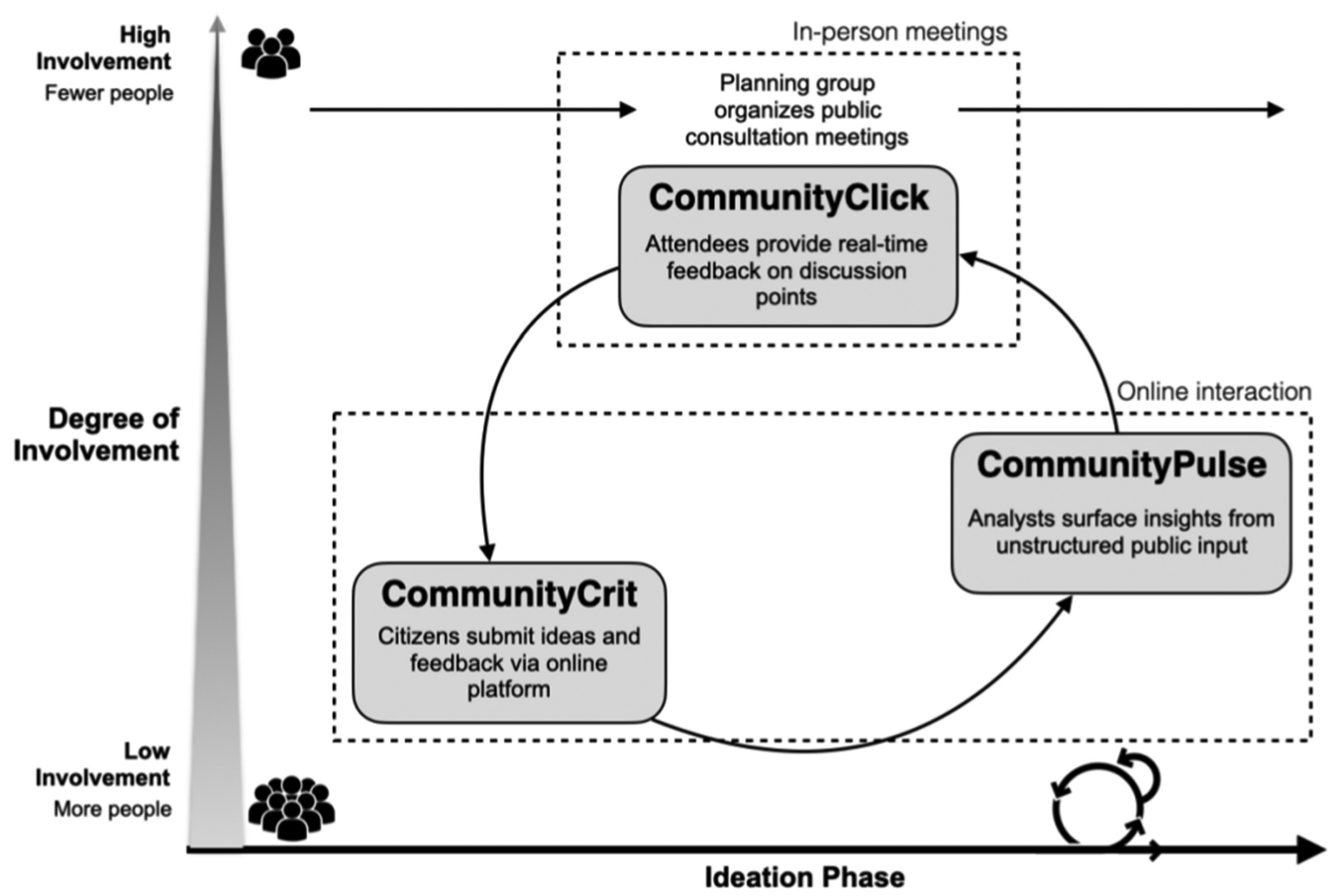

Fig. 4. Example of how three existing Open Civic Design platforms (CommunityCrit, CommunityClick, and CommunityPulse) could be integrated to augment traditional in-person modes of civic participation to realize the vision for the Open Civic Design framework for the ideation phase of a hypothetical urban design and planning process.

summarize and analyze the meeting notes along with attendees' feedback. The system was deployed as a field experiment at a town hall meeting in Amherst, Massachusetts where attendees discussed parking issues in the city. The results suggest that CommunityClick provided a voice to participants and enabled organizers to author more comprehensive and accurate reports.

Lessons learned from the deployment of CommunityCrit inspired a new platform called CommunityPulse to help civic leaders analyze large-scale civic input gathered through online platforms. CommunityPulse [55] combines visualization and machine learning methods to help civic leaders analyze a large amount of free-form textual input from the public to surface hidden issues, needs, and priorities of the community. An evaluation with 15 civic leaders suggests that the platform surfaces deeper insights and requires less effort and expertise than current civic data analysis methods. It is worth mentioning that CommunityPulse is a single-analyst interactive system that addresses the lack of public input analysis tools by utilizing novel computational techniques to surface key insights that are hidden in unstructured public input. However, CommunityPulse does not support collaborative sense-making tasks. We envision building upon this work by adding citizen-sourcing components that allow members of the public to take part in the analysis process to enable more effective and inclusive utilization of public input.

Figure 4 depicts a hypothetical use case where these platforms could be integrated to facilitate a variety of hybrid participation options (i.e., online and in-person) at different stages of a structured civic design process based on the Open Civic Design framework. Each platform could serve in complementary ways in supporting an end-to-end urban design and planning process. CommunityCrit could solicit online involvement related to proposing ideas, decomposing and allocating activities, and submitting feedback. CommunityClick could be used at in-person planning meetings to gather input from attendees and the results could be reported back to the larger

Digital Government: Research and Practice, Vol. 2, No. 4, Article 31. Publication date: December 2021. 
audience by posting summaries of in-person meetings online. CommunityPulse could offer a range of mediumand high-involvement roles and activities related to analyzing gathered input through both in-person and online participation to uncover community reflections and priorities. These three platforms could potentially be used during other phases of a civic design process, such as problem defining and prototyping. Each of these tools targets a specific challenge in the civic design process. However, none of them offer a unified platform that provides engagement opportunities from the early stages of brainstorming and defining problems to the final stage of implementing solutions. The Open Civic Design framework's vision suggests an ecosystem of tools to support a more comprehensive and inclusive open civic design process.

\section{DISCUSSION AND FUTURE WORK}

We discuss some of the considerations involved in realizing our vision for Open Civic Design, including operationalizing, implementing, and testing the Open Civic Design framework. We describe the affordances and challenges associated with the three key goals of the framework: (1) to promote inclusive and sustained participation in civics; (2) to facilitate effective management of large-scale participation; and (3) to provide a structured process for achieving effective solutions. We also discuss directions for future work.

\subsection{Promoting Inclusive and Sustained Participation in Civics}

Public participation in civic design should give voice and agency to those most affected by design decisions. Government organizations also recognize the need to include external problem solvers to improve the efficiency and quality of their processes and policies [81]. Several important considerations for improving inclusivity in civics as suggested by the Open Civic Design framework are described below.

5.1.1 Support Physical, Virtual, and Hybrid Participation. Both physical and virtual modes of engagement are important. Face-to-face meetups are the best way to secure high involvement and investment in the project [43], but costs and constraints associated with participation (e.g., time, transportation, childcare) limit their scale and inclusiveness [41, 52,98]. Virtual engagement activities lower financial, geographic, and temporal barriers to participation and can reach larger and more inclusive groups than face-to-face efforts [17, 77, 82], yet online-only processes pose a potential for disconnect between stakeholders, place, and problems [98]. The Open Civic Design framework suggests augmenting existing in-person participation modes through digital technologies (e.g., online platforms and mobile apps) and hybrid in-situ technologies (e.g., kiosks [48], public displays [107], and iClickers [56]). Such technologies can help scale up participation by offering additional points of entry with flexible and accessible participation options. One challenge is the so-called "digital divide": a nontrivial proportion of the U.S. and global populations-typically those who are already marginalized in civic processes-still lack the technology access [96] and/or digital literacy [38] needed to participate. This means that the typical web user is likely to be White, middle- or upper-class, English speaking, and higher educated [16, 98]. In the future, civic researchers could explore recruiting strategies to reach people with limited access, such as partnering with groups already promoting civic engagement among underrepresented populations [77].

5.1.2 Match People to Activities that Align with their Skills and Availability. Citizens have varying availability to participate, as well as diverse types and levels of expertise. To accommodate this, the Open Civic Design framework allows for multiple different types of simultaneous participation. Individuals can be core, active, occasional, peripheral, or transactional participants in the "community of practice," where each role requires a different level of availability and expertise [66]. The Open Civic Design framework draws on crowdsourcing to suggest breaking down large and complex activities into a series of micro-activities that can be aligned with a particular participants' skills, interests, and availability to enhance the effectiveness of their involvement [61, $77,90]$. One challenge is that it is still unclear how best to assign activities based on participants' skills: should a platform automatically assign roles, or should participants be able to select their own assignments [61]? Future

Digital Government: Research and Practice, Vol. 2, No. 4, Article 31. Publication date: December 2021. 
work could investigate this question through empirical studies that integrate insights about task assignment from workflow management research [99].

5.1.3 Offer a Range of Incentive Mechanisms. While some studies have found that civic technology broadens participation by marginalized populations $[68,79]$, others have found that civic tech attracts the same individuals who already engage in traditional civic processes $[21,57]$-primarily those with an intrinsic interest in civic duty [111]. Crowdsourcing methods can motivate participation through a variety of incentives, both intrinsic (e.g., improving society, learning, social experience) and extrinsic (e.g., prizes, status, career development) [63, 98]. There is no single set of incentive mechanisms that will work for all people and activities, so offering a wide spectrum of motivational factors may increase the diversity of participation. It remains a challenge to understand which incentive mechanisms are most effective for different contexts, populations, and activities. For instance, studies on creativity find that either extrinsic incentives (i.e., those based on competition) or intrinsic incentives (i.e., those based on cooperation) can produce higher quantity and quality of ideas. A key future direction is to investigate "coopetition" models, which combine the features of competition and cooperation to encourage more open sharing of ideas and higher creative output than either model could produce in isolation [36].

5.1.4 Provide Paths for Citizens to Take on Responsibilities and Decision-Making Power. Traditional civic problem-solving initiatives have been driven by government agencies in a top-down manner. Even when they attempt to get community input, they often treat citizens as "sensors" and leave them with little power or control over decision-making [9]. Furthermore, the social dynamics of in-person workshops privileges citizens with oversized personalities. There is a danger that initiatives can be co-opted by elites that have better access and who may dominate the process at the expense of the public [49]. The Open Civic Design framework partially mitigates these issues by allowing citizens to flow between high-involvement and low-involvement activities, and by emphasizing the synthesis of community input and the iterative refinement of proposals. Despite this, power imbalances-where individuals are privileged or oppressed based on their intersecting social identity group membership (e.g., race, class, gender)-will remain a challenge [28]. One area for future research is to develop a better understanding of how to mitigate systemic power asymmetries that may manifest in open civic design initiatives.

\subsection{Facilitate Effective Management of Large-Scale Participation}

Scaling up and diversifying civic engagement will introduce challenges associated with how to effectively manage large-scale participation. Existing public engagement initiatives are often poorly organized and fail to adequately manage to get input from all stakeholders-who hold differing and often conflicting perspectives-and this can result in a failure to achieve consensus on public decisions [71]. The following considerations seek to address these issues in the context of the Open Civic Design framework.

5.2.1 Create Processes for Decomposing Goals into Activities. Management of innovation processes can be burdensome when there are high levels of dynamic, transient participation [53]. The Open Civic Design framework proposes to leverage mechanisms from crowdsourcing to provide activity management tools for a central planning group. The goal is for initiatives to succeed via decentralized organization of modular activities that can be performed in parallel by civically motivated participants [63]. Yet, several challenges remain regarding how to manage large-scale participation and workflows, including: focusing the crowd's attention and guiding them in productive ways [7,53]; dealing with the ad-hoc nature of how participants perform activities, particularly when the work is open-ended and loosely defined, or requires synchronous collaboration [61, 106]; and breaking the problem down into manageable pieces, and subsequently weaving the solution back together and dealing with interdependencies [61]. Future work could explore the tradeoffs between providing individual agency versus directing the crowd [85], and between offering quick, accessible activities versus more involved activities that require deeper consideration of contextual factors and other participants' contributions [77]. One

Digital Government: Research and Practice, Vol. 2, No. 4, Article 31. Publication date: December 2021. 
promising direction is to investigate how the concept of "flash organizations"-crowds that assemble quickly into organizations with roles, teams, and hierarchies to achieve complex outcomes with minimal managerial oversight-could work within a civic context [106].

5.2.2 Provide Support for Scaffolding Activities. Citizens who join a civic design initiative may need to be briefed on the history and context of the project and the details of how they can perform various activities. Additionally, the nature of certain activities and the associated online tools to support them often require participants to have specific skills or expertise that everyday citizens may lack $[6,15,84]$, such as software development skills [81]. The crowdsourcing literature offers some techniques to scaffold engagement opportunities such as providing just-in-time training with step-by-step tutorials [33], creating activities with low-skill thresholds [62], and decomposing work into smaller, granular tasks [83]. While some crowdsourcing systems guide participants to learn domain-specific content knowledge and processes for complex design activities [74], this remains an area of active research. Future research could explore how to best support learning in crowdsourcing environments, for example by conceptualizing the participants as a "community of practice" [66] or a "community of interest" (i.e., stakeholders from different communities of practice with a collective concern for the resolution of a particular problem) [39].

5.2.3 Create Tools to Enable Productive Collaboration and Deliberation among the Crowd. Civic processes suffer from intrinsic conflict because of widely varying motivations, values, privileges, and opinions of the various stakeholders. There is often also a communication disconnect and a gap in understanding among government agencies, design professionals, and local citizens, largely because they belong to different "communities of practice" and thus use different languages and knowledge systems [39, 66]. Using virtual engagement to broaden participation brings additional challenges, such as coordination costs and process losses, as peer-to-peer communication often breaks down with too many people involved [60].

To promote collaboration and deliberation, the Open Civic Design framework draws upon insights from crowdsourcing to suggest that crowd-civic systems should include both synchronous and asynchronous communication modes as well as decision-support tools. Asynchronous engagement can enable large-scale, many-to-many discussions [25, 85]. Decision-support tools, such as structured online debate forums, can support agenda setting and shared understanding of issues by allowing crowd members to share opinions, post comments and questions, take positions, make arguments, and view summaries on key points of view [53]. For example, an analysis of two crowdsourced policymaking processes found that crowdsourcing can facilitate high-quality deliberation according to standards of deliberative democracy [4]. One salient challenge is that in many wicked problems consensus is unattainable [16], and some scholars have even argued that consensus is counterproductive because it can lead to marginalization of minority viewpoints [78], and that often the best democratic decisions emerge from the product of dissensus (i.e., tolerant disagreement) [67]. One avenue for future work is to explore the trade-offs between consensus and dissensus in decision-making.

5.2.4 Leverage Crowd Reviewing Mechanisms to Synthesize Large Amounts of Data. To effectively solve complex civic problems, the public needs to efficiently and effectively aggregate, analyze, and synthesize enormous volumes of multi-faceted, contextually rich data residing in different sources. The use of such data can support evidence-based policymaking [51]. However, due to the sheer volume of data that may be collected and generated-especially if crowdsourcing techniques are used-stakeholders may become overloaded, leaving much data unanalyzed and unused in policymaking processes [2,78]. To enable collaborative data analysis and synthesis, initiatives that leverage the Open Civic Design framework could borrow crowdsourcing approaches that have enabled crowds to analyze video data [65], synthesize diverse online information into organized outlines [73], and synthesize complex ill-structured qualitative data to uncover themes and concepts [6]. Risks associated with data security and privacy $[10,98,112]$ remain an open challenge; future research could investigate how to balance tradeoffs among privacy, transparency, and community insight [77].

Digital Government: Research and Practice, Vol. 2, No. 4, Article 31. Publication date: December 2021. 
5.2.5 Establish Quality Control Methods. Open Civic Design processes will likely suffer from quality control issues that may arise from various scenarios, such as participants attempting to complete activities without the necessary skills $[6,15,84]$ or nefarious actors contributing spam or false information [112]. Initiatives that leverage the Open Civic Design framework could take advantage of quality control methods from crowdsourcingsuch as peer review, expert review, majority consensus, and comparison to gold standards-that can quickly identify participants who behave irresponsibly or misunderstand the task [5, 34, 42, 113]. While many of these approaches work well for closed-ended activities, it remains an active research area to assure high-quality output from activities that are open-ended or require high levels of expertise [61].

\subsection{Provide a Structured Process for Achieving Effective Solutions}

Complex civic challenges are dynamic, ill-defined, and interdependent on social factors, and are thus resistant to conventional solution approaches [92]. Furthermore, major challenges arise during solution implementation due to issues associated with attempting to integrate into or change the broader political, economic, cultural, and organizational context [89]. Some design scholars have argued that the complexity of civic challenges precludes the possibility of an optimized solution, and that satisficed solutions (i.e., those that are merely satisfactory) must be sought instead [89]. Below we unpack key considerations for creating a structured process to achieve effective solutions, as suggested by the Open Civic Design framework.

5.3.1 Engage in Infrastructuring. Prior research emphasizes the importance of taking stock of community assets and establishing essential infrastructure before embarking on a civic design process. Infrastructuring includes forming lasting and robust relationships among stakeholders, practices, and technologies [27, 32, 45, 46] and securing a regular influx of resources (e.g., money, people). To address these issues, initiatives guided by the Open Civic Design framework might create high-involvement roles dedicated to the task of infrastructuring and preparing the innovation ecosystem. A risk here is that infrastructuring places too much burden on a few leaders before the community-driven processes even get off the ground. Future research could investigate strategies for maintaining continuity during infrastructuring despite transient participation.

5.3.2 Guide Citizens in Broad Exploration of Problems and Solutions. The complexity and scope of civic challenges suggests the need for broad exploration of the problem and solution spaces [8]. The Open Civic Design framework considers how to guide citizens in problem solving by structuring a design thinking process. The framework can support a broad exploration of problems by gathering crowdsourced information about civic issues that are locally relevant and full of rich, contextual information such as images, location markers, and stories of personal experiences $[43,79,80,112]$. The framework can also promote solution ideation by helping citizens collectively create more ideas than they could generate in isolation. Lessons from crowd ideation research show that strategies such as showing participants creative and diverse ideas from others [100] and using experienced facilitators to offer inspiration [23] can lead to better ideas. A challenge might arise if citizens contribute shortterm solutions that address the symptoms of problems rather than long-term solutions to the underlying causes of problems [43]. One topic for future work is to explore ways of encouraging citizens to attend to the structural causes of civic issues and to generate solution concepts that address issues of long-term sustainability.

5.3.3 Facilitate Iterative and Transparent Testing of Potential Solutions. Numerous factors can preclude community-driven initiatives from implementing proposed solutions. Goals and circumstances often change throughout a civic design process, sometimes causing initiatives to end after the ideation phase before any ideas get implemented [70, 81]. Government agencies are seldom willing or able to incorporate citizen-sourced data and solutions into their processes due to rigid and time-consuming fiduciary, legal, political, and administrative constraints $[2,82,83]$. Policy windows-that is, opportunities for action on given initiatives-open only for short time periods and require consensus on the problem, the policy solution, and the political will of citizens and government leaders to implement solutions despite potential downsides [58].

Digital Government: Research and Practice, Vol. 2, No. 4, Article 31. Publication date: December 2021. 
The Open Civic Design framework allows an initiative to dynamically adapt to the current needs or even loop back to redo a particular phase if the goals are not met. It emphasizes a trial-and-error approach and the testing of incremental solutions in real world contexts to deal with the complexity of wicked problems [89]. For example, urban planners have begun using an approach called "tactical urbanism" in which small, temporary installations are used to demonstrate viability and spur momentum for larger projects [75]. An incremental solution that has been piloted and assessed by citizens will be perceived as more legitimate and more likely to get adopted [41]. However, the iterative nature of this process, as well as the dynamic, inconsistent nature of citizen participation, creates the potential for information to be forgotten or lost.

Future work could focus on identifying strategies to support "institutional memory" such as keeping a transparent history of participant actions, contributions, and choices [59]. Additionally, more research is needed to help guide public agencies in creating and modifying structures and processes to make them amenable to implementing solutions from open civic design initiatives [82]. One proposed strategy is to embed open civic design initiatives into the larger context of a government agency's core agenda [86]. Another potential topic of research is to study citizen innovators operating outside formal processes-akin to "lead user innovators" [50]-to look for patterns in the way they approach and solve problems and to capture their real-world trial-and-error insights to better understand the conditions under which solutions are likely to be implemented, adopted, and sustained. These insights could then be leveraged to potentially reshape open civic design processes and platforms.

\section{LIMITATIONS}

We acknowledge that there are many inherent limitations of theoretical frameworks. Many uncertainties and potentially unforeseen challenges will arise when trying to implement the Open Civic Design framework in practice. We attempted to partially mitigate this limitation by describing considerations for practical implementation, including the need to work closely with key stakeholders and government agencies. Another limitation is that we have not empirically evaluated the framework or compared it against other frameworks; the hypothetical scenarios and case studies of existing civic design initiatives provide initial intuitions for the validity and utility of the Open Civic Design framework. While those projections are contrived, we attempted to present scenarios that feel plausible based on our own experiences with real-world civic design initiatives and are largely representative of other civic design initiatives based on a review of the relevant literature. Future work might focus on creating a guidebook or platform for open civic design based on the framework and studying how it is appropriated by civic problem solvers. Disseminating this framework into the digital government community might increase the likelihood that a government or civic initiative will attempt this approach. Field reports that emerge from efforts to put the framework into practice will lead to new insights that could be used to further refine the framework itself.

\section{CONCLUSION}

We have presented a theoretical framework for Open Civic Design that envisions a structured process for engaging and managing citizens in civic problem-solving at large scale by providing a wide variety of flexible and appropriately matched participation options. The Open Civic Design framework integrates existing conceptual frameworks from public participation, crowdsourcing, and design thinking to leverage their strengths and mitigate their individual limitations. While the Open Civic Design framework has not been empirically tested, we have described several real-world case studies to illustrate the potential to inspire and guide more expansive engagement for participatory initiatives. The Open Civic Design framework outlines a new way to leverage the collective intelligence of citizens in creating civic solutions in a more inclusive, large-scale, and effective manner.

\section{ACKNOWLEDGMENTS}

We thank Brian McInnis and Roy Pea for insightful discussions and feedback. We also acknowledge the contributions of Joanne Cho, Lauren Liu, Sanika Moharana, Alejandro Panduro, and Eric Richards.

Digital Government: Research and Practice, Vol. 2, No. 4, Article 31. Publication date: December 2021. 


\section{REFERENCES}

[1] Tanja Aitamurto and Kaiping Chen. 2017. The value of crowdsourcing in public policymaking: Epistemic, democratic and economic value. The Theory and Practice of Legislation 5, 1 (2017), 55-72.

[2] Tanja Aitamurto, Kaiping Chen, Ahmed Cherif, Jorge Saldivar Galli, and Luis Santana. 2016. Civic CrowdAnalytics: Making sense of crowdsourced civic input with big data tools. In Proceedings of the 20th International Academic Mindtrek Conference (October 17-18, 2016, Tampere, Finland). ACM, New York, 86-94.

[3] Tanja Aitamurto and Hélène Landemore. 2015. Five design principles for crowdsourced policymaking: Assessing the case of crowdsourced off-road traffic law in Finland. Journal of Social Media for Organizations 2, 1 (2015), 1-19.

[4] Tanja Aitamurto and Jorge Saldivar. 2017. Examining the quality of crowdsourced deliberation: Respect, reciprocity and lack of common-good orientation. In Proceedings of the 2017 CHI Conference Extended Abstract on Human Factors in Computing Systems (CHI'17) (May 6-11, 2017, Denver, Colorado). ACM, New York, 2314-2321.

[5] M. Allahbakhsh, B. Benatallah, A. Ignjatovic, H. R. Motahari-Nezhad, E. Bertino, and S. Dustdar. 2013. Quality control in crowdsourcing systems: Issues and directions. IEEE Internet Computing 17, 2 (2013), 76-81.

[6] Paul André, Aniket Kittur, and Steven P. Dow. 2014. Crowd synthesis: Extracting categories and clusters from complex data. In Proceedings of the 17th ACM Conference on Computer Supported Cooperative Work \& Social Computing (CSCW'14), Febrauary (15-19, 2014, Baltimore, Maryland). ACM, New York, 989-998.

[7] Aggeliki Androutsopoulou, Nikos Karacapilidis, Euripidis Loukis, and Yannis Charalabidis. 2017. Towards an integrated and inclusive platform for open innovation in the public sector. In E-Democracy-Privacy-Preserving, Secure, Intelligent E-Government Services (Communications in Computer and Information Science), 228-243.

[8] Ernesto Arias, Hal Eden, Gerhard Fischer, Andrew Gorman, and Eric Scharff. 2000. Transcending the individual human mind-Creating shared understanding through collaborative design. ACM Transactions on Computer-Human Interaction 7, 1 (2000), 84-113.

[9] Sherry R. Arnstein. 1969. A ladder of citizen participation. Journal of the American Institute of Planners 35, 4 (1969), $216-224$.

[10] Mariam Asad and Christopher A. Le Dantec. 2015. Illegitimate civic participation: Supporting community activists on the ground. In Proceedings of the 18th ACM Conference on Computer Supported Cooperative Work \& Social Computing (CSCW'15) (March 14-18, 2015, Vancouver, Canada). ACM, New York, 1694-1703.

[11] Mariam Asad, Christopher A. Le Dantec, Becky Nielsen, and Kate Diedrick. 2017. Creating a sociotechnical API: Designing city-scale community engagement. In Proceedings of the 2017 CHI Conference on Human Factors in Computing Systems (CHI'17) (May 6-11, 2017, Denver, Colorado). ACM, New York, 2295-2306.

[12] Ted Becker. 2001. Rating the impact of new technologies on democracy. Communications of the ACM 44, 1 (2001), 39-43.

[13] Erling Björgvinsson, Pelle Ehn, and Per-Anders Hillgren. 2010. Participatory design and democratizing innovation. In Proceedings of the 11th Biennial Participatory Design Conference (PDC'10) (November 29-December 3, 2010, Sydney, Australia). ACM, New York, 41-50.

[14] Kirsten Boehner and Carl DiSalvo. 2016. Data, design and civics: An exploratory study of civic tech. In Proceedings of the 2016 CHI Conference on Human Factors in Computing Systems (CHI'16) (May 7-12, 2016, San Jose, California). ACM, New York, 2970-2981.

[15] Daren C. Brabham. 2008. Crowdsourcing as a model for problem solving: An introduction and cases. Convergence 14, 1 (2008), 75-90.

[16] Daren C. Brabham. 2009. Crowdsourcing the public participation process for planning projects. Planning Theory 8, 3 (2009), $242-262$.

[17] Daren C. Brabham, Thomas W. Sanchez, and Keith Bartholomew. 2010. Crowdsourcing public participation in transit planning: Preliminary results from the next stop design case. In Proceedings of the Transportation Research Board 89th Annual Meeting, January (10-14, 2010, Washington, D.C.). The National Academies Press, Washington, D.C.

[18] Tim Brown. 2008. Design thinking. Harvard Business Review 86, 6 (2008), 84-92.

[19] John M. Bryson, Kathryn S. Quick, Carissa Schively Slotterback, and Barbara C. Crosby. 2013. Designing public participation processes. Public Administration Review 73, 1 (2013), 23-34.

[20] Richard Buchanan. 1992. Wicked problems in design thinking. Design Issues 8, 2 (1992), 5-21.

[21] Marta Cantijoch, Silvia Galandini, and Rachel Gibson. 2016. "It's not about me, it's about my community": A mixed-method study of civic websites and community efficacy. New Media \& Society 18, 9 (2016), 1896-1915.

[22] C. M. L. Chan. 2013. From open data to open innovation strategies: Creating e-services using open government data. In Proceedings of the 46th Hawaii International Conference on System Sciences (January 7-10, 2013, Wailea, Hawaii). IEEE, New York, 1890-1899.

[23] Joel Chan, Steven Dang, and Steven P. Dow. 2016. Improving crowd innovation with expert facilitation. In Proceedings of the 19th ACM Conference on Computer-Supported Cooperative Work \& Social Computing (CSCW'16) (February 27 - March 2, 2016, San Francisco, California). ACM, New York, 1223-1235.

[24] Caron Chess and Kristen Purcell. 1999. Public participation and the environment: Do we know what works? Environmental Science and Technology 33, 16 (1999), 2685-2692.

[25] Stephen Coleman and John Gotze. 2001. Bowling Together: Online Public Engagement in Policy Deliberation. Hansard Society, London, U.K.

Digital Government: Research and Practice, Vol. 2, No. 4, Article 31. Publication date: December 2021. 
[26] Seth Cooper, Firas Khatib, Adrien Treuille, Janos Barbero, Jeehyung Lee, Michael Beenen, Andrew Leaver-Fay, David Baker, Zoran Popović, and Foldit Players. 2010. Predicting protein structures with a multiplayer online game. Nature 466, 7307 (2010), 756-760.

[27] Eric Corbett and Christopher A. Le Dantec. 2018. Exploring trust in digital civics. In Proceedings of the 2018 Designing Interactive Systems Conference (DIS'18) (June 9-13, Hong Kong, China). ACM, New York, 9-20.

[28] Sasha Costanza-Chock. 2020. Design fustice: Community-led Practices to Build the Words we Need. The MIT Press, Cambridge, MA.

[29] Nigel Cross. 1982. Designerly ways of knowing. Design Studies 3, 4 (1982), 221-227.

[30] Michael X. Delli Carpini and Scott Keeter. 1996. What Americans Know About Politics and Why It Matters. Yale University Press, New Haven, CT.

[31] Kevin C. Desouza and Akshay Bhagwatwar. 2014. Technology-enabled participatory platforms for civic engagement: The case of U.S. cities. Fournal of Urban Technology 21, 4 (2014), 25-50.

[32] Carl DiSalvo and Christopher A. Le Dantec. 2017. Civic design. Interactions 24, 6 (2017), 66-69.

[33] Mira Dontcheva, Robert R. Morris, Joel R. Brandt, and Elizabeth M. Gerber. 2014. Combining crowdsourcing and learning to improve engagement and performance. In Proceedings of the SIGCHI Conference on Human Factors in Computing Systems (CHI'14) (April 26 May 1, 2014, Toronto, Canada). ACM, New York, 3379-3388.

[34] Steven Dow, Anand Kulkarni, Scott Klemmer, and Björn Hartmann. 2012. Shepherding the crowd yields better work. In Proceedings of the ACM 2012 Conference on Computer-Supported Cooperative Work (CSCW'12) (February 11-15, 2012, Seattle, Washington). ACM, New York, 1013-1022.

[35] Eric Duhaime, Gary M. Olson, and Thomas W. Malone. 2015. Broad Participation in Collective Problem Solving Can Influence Participants and Lead to Better Solutions: Evidence from the MIT Climate CoLab. Massachusetts Institute of Technology, Cambridge, MA.

[36] Mehdi Elmoukhliss, Damien Renard, Zhenzhen Zhao, and Christine Balague. 2016. Crowdsourcing collective intelligence through coopetition. In Proceedings of the 2016 Collective Intelligence Conference (June 1-3, 2016, New York, New York). ACM, New York.

[37] Enzo Falco and Reinout Kleinhans. 2018. Digital participatory platforms for co-production in urban development: A systematic review. International fournal of E-Planning Research (IFEPR) 7, 3 (2018), 52-79.

[38] Enzo Falco and Reinout Kleinhans. 2018. Beyond technology: Identifying local government challenges for using digital platforms for citizen engagement. International fournal of Information Management 40, 17-20.

[39] Gerhard Fischer. 2001. Communities of interest: Learning through the interaction of multiple knowledge systems. In Proceedings of the 24th Annual Information Systems Research Seminar in Scandinavia (IRIS 24) (August 11-14, 2001, Bergen, Norway). University of Bergen, Bergen, Norway.

[40] Archon Fung. 2006. Varieties of participation in complex governance. Public Administration Review 66, s1 (2006), 66-75.

[41] Archon Fung. 2015. Putting the public back into governance: The challenges of citizen participation and its future. Public Administration Review 75, 4 (2015), 513-522.

[42] Ujwal Gadiraju, Ricardo Kawase, Stefan Dietze, and Gianluca Demartini. 2015. Understanding malicious behavior in crowdsourcing platforms: The case of online surveys. In Proceedings of the 33rd Annual ACM Conference on Human Factors in Computing Systems (CHI'15) (April 18-23, 2015, Seoul, Republic of Korea). ACM, New York, 1631-1640.

[43] Daniel Gooch, Matthew Barker, Lorraine Hudson, Ryan Kelly, Gerd Kortuem, Janet Van Der Linden, Marian Petre, Rebecca Brown, Anna Klis-Davies, Hannah Forbes, Jessica Mackinnon, Robbie Macpherson, and Clare Walton. 2018. Amplifying quiet voices: Challenges and opportunities for participatory design at an urban scale. ACM Transactions on Computer-Human Interaction 25, 1 (2018), 2 .

[44] Daniel Gooch, Annika Wolff, Gerd Kortuem, and Rebecca Brown. 2015. Reimagining the role of citizens in smart city projects. In Adjunct Proceedings of the 2015 ACM International foint Conference on Pervasive and Ubiquitous Computing and Proceedings of the 2015 ACM International Symposium on Wearable Computers (UbiComp/ISWC'15) (September 7-11, 2015, Osaka, Japan). ACM, New York, $1587-1594$.

[45] Derek L. Hansen, Jes A. Koepfler, Paul T. Jaeger, John C. Bertot, and Tracy Viselli. 2014. Civic action brokering platforms: Facilitating local engagement with ACTion Alexandria. In Proceedings of the 17th ACM Conference on Computer Supported Cooperative Work \& Social Computing (CSCW'14) (February 15-19, 2014, Baltimore, Maryland). ACM, New York, 1308-1322.

[46] Mike Harding, Bran Knowles, Nigel Davies, and Mark Rouncefield. 2015. HCI, civic engagement \& trust. In Proceedings of the 33rd Annual ACM Conference on Human Factors in Computing Systems (CHI'15) (April 18-23, 2015, Seoul, Republic of Korea). ACM, New York, 2833-2842.

[47] David Harvey. 2003. The right to the city. International fournal of Urban and Regional Research 27, 4 (2003), 939-941.

[48] Kurtis Heimerl, Brian Gawalt, Kuang Chen, Tapan S. Parikh, and Bjorn Hartmann. 2012. Communitysourcing: Engaging local crowds to perform expert work via physical kiosks. In Proceedings of the SIGCHI Conference on Human Factors in Computing Systems (CHI'12) (May 5-10, 2012, Austin, Texas). ACM, New York, 1539-1548.

[49] Dennis Hilgers and Christoph Ihl. 2010. Citizensourcing: Applying the concept of open innovation to the public sector. The International fournal of Public Participation 4, 1 (2010), 67-88.

[50] Eric von Hippel. 2005. Democratizing Innovation. The MIT Press, Cambridge, MA.

Digital Government: Research and Practice, Vol. 2, No. 4, Article 31. Publication date: December 2021. 
[51] Johann Hochtl, Peter Parycek, and Ralph Schollhammer. 2016. Big data in the policy cycle: Policy decision making in the digital era. fournal of Organizational Computing and Electronic Commerce 26, 1-2 (2016), 147-169.

[52] Judith E. Innes and David E. Booher. 2005. Reframing public participation: Strategies for the 21st century. Planning Theory \& Practice 5, 4 (2005), 419-436.

[53] Joshua Introne, Robert Laubacher, Gary Olson, and Thomas Malone. 2011. The Climate CoLab: Large scale model-based collaborative planning. In Proceedings of the 2011 International Conference on Collaboration Technologies and Systems (CTS), 40-47.

[54] Renee A. Irvin and John Stansbury. 2004. Citizen participation in decision making: Is it worth the effort? Public Administration Review 64, 1 (2004), 55-65.

[55] Mahmood Jasim, Enamul Hoque, Ali Sarvghad, and Narges Mahyar. 2021. CommunityPulse: Facilitating community input analysis by surfacing hidden insights, reflections, and priorities. In Proceedings of the 2021 Designing Interactive Systems Conference (DIS'21) (June 28- July 2, 2021, Virtual Event). ACM, New York, 846-863.

[56] Mahmood Jasim, Pooya Khaloo, Somin Wadhwa, Amy X. Zhang, Ali Sarvghad, and Narges Mahyar. 2020. CommunityClick: Capturing and reporting community feedback from town halls to improve inclusivity. In Proceedings of the ACM on Human-Computer Interaction (4, CSCW3), 1-32. https://dl.acm.org/doi/10.1145/3432912

[57] Andrea Kavanaugh, John M. Carroll, Mary Beth Rosson, Debbie D. Reese, and Than T. Zin. 2005. Participating in civil society: The case of networked communities. Interacting with Computers 17, 1 (2005), 9-33.

[58] John W. Kingdon and James A. Thurber. 1984. Agendas, Alternatives, and Public Policies. Little, Brown, Boston, MA.

[59] Peter Kinnaird, Laura Dabbish, Sara Kiesler, and Haakon Faste. 2013. Co-worker transparency in a microtask marketplace. In Proceedings of the 2013 Conference on Computer-Supported Cooperative Work (CSCW'13) (February 23-27, 2013, San Antonio, Texas). ACM, New York, 1285-1290.

[60] Aniket Kittur and Robert E. Kraut. 2008. Harnessing the wisdom of crowds in Wikipedia: Quality through coordination. In Proceedings of the 2008 ACM Conference on Computer-Supported Cooperative Work (CSCW'08) (November 8-12, 2008, San Diego, California). ACM, New York, 37-46.

[61] Aniket Kittur, Jeffrey V. Nickerson, Michael Bernstein, Elizabeth Gerber, Aaron Shaw, John Zimmerman, Matt Lease, and John Horton. 2013. The future of crowd work. In Proceedings of the 2013 Conference on Computer-Supported Cooperative Work (CSCW'13) (February 23-27, 2013, San Antonio, Texas). ACM, New York, 1301-1318.

[62] Aniket Kittur, Boris Smus, Susheel Khamkar, and Robert E. Kraut. 2011. CrowdForge: Crowdsourcing complex work. In Proceedings of the 24th Annual ACM Symposium on User Interface Software and Technology (UIST'11) (October 16-19, 2011, Santa Barbara, California). ACM, New York, 43-52.

[63] Karim R. Lakhani and Jill A. Panetta. 2007. The principles of distributed innovation. Innovations: Technology, Governance, Globalization Summer 2, 3 (2007), 97-112.

[64] Hélène Landemore. 2017. Democratic Reason: Politics, Collective Intelligence, and the Rule of the Many. Princeton University Press, Princeton, N.J.

[65] Walter S. Lasecki, Mitchell Gordon, Danai Koutra, Malte F. Jung, Steven P. Dow, and Jeffrey P. Bigham. 2014. Glance: Rapidly coding behavioral video with the crowd. In Proceedings of the 27th Annual ACM Symposium on User Interface Software and Technology (UIST'14) (October 5-8, 2014, Honolulu, Hawaii). ACM, New York, 551-562.

[66] Jean Lave and Etienne Wenger. 1991. Situated Learning: Legitimate Peripheral Participation. Cambridge University Press, Cambridge, U.K.

[67] Christopher A. Le Dantec. 2017. Design through collective action/Collective action through design. Interactions 24, 1 (2017), 24-30.

[68] Christopher A. Le Dantec, Mariam Asad, Aditi Misra, and Kari E. Watkins. 2015. Planning with crowdsourced data: Rhetoric and representation in transportation planning. In Proceedings of the 18th ACM Conference on Computer Supported Cooperative Work \& Social Computing (CSCW'15) (March 14-18, 2015, Vancouver, Canada). ACM, New York, 1717-1727.

[69] Christopher A. Le Dantec and Carl DiSalvo. 2013. Infrastructuring and the formation of publics in participatory design. Social Studies of Science 43, 2 (2013), 241-264.

[70] Melissa Lee, Esteve Almirall, and Jonathan Wareham. 2015. Open data and civic apps: First-generation failures, second-generation improvements. Communications of the ACM 59, 1 (2015), 82-89.

[71] Peter Levine, Archon Fung, and John Gastil. 2005. Future directions for public deliberation. fournal of Deliberative Democracy 1,1 (2005), 3.

[72] Dennis Linders. 2012. From e-government to we-government: Defining a typology for citizen coproduction in the age of social media. Government Information Quarterly 29, 4 (2012), 446-454.

[73] Kurt Luther, Nathan Hahn, Steven P. Dow, and Aniket Kittur. 2015. Crowdlines: Supporting synthesis of diverse information sources through crowdsourced outlines. In Proceedings of the 3rd AAAI Conference on Human Computation and Crowdsourcing (HCOMP-15) (November 8-11, 2015, San Diego, California). The AAAI Press, Palo Alto, CA.

[74] Kurt Luther, Amy Pavel, Wei Wu, Jari-Lee Tolentino, Maneesh Agrawala, Björn Hartmann, and Steven P. Dow. 2014. CrowdCrit: Crowdsourcing and aggregating visual design critique. In Proceedings of the Companion Publication of the 17th ACM Conference on

Digital Government: Research and Practice, Vol. 2, No. 4, Article 31. Publication date: December 2021. 
Computer Supported Cooperative Work \& Social Computing (CSCW'14) (February 15-19, 2014, Baltimore, Maryland). ACM, New York, 21-24.

[75] Mike Lydon and Anthony Garcia. 2015. A tactical urbanism how-to. In Tactical Urbanism. Springer, 171-208.

[76] Anne Macintosh. 2004. Characterizing e-participation in policy-making. In Proceedings of the 37th Hawaii International Conference on System Sciences (January 5-8, 2004, Big Island, Hawaii). IEEE, New York, 1-10.

[77] Narges Mahyar, Michael R. James, Michelle M. Ng, Reginald A. Wu, and Steven P. Dow. 2018. CommunityCrit: Inviting the public to improve and evaluate urban design ideas through micro-activities. In Proceedings of the 2018 CHI Conference on Human Factors in Computing Systems (CHI'18) (April 21-26, 2018, Montreal, Ont., Canada). ACM, New York, Paper No. 195.

[78] Narges Mahyar, Diana V. Nguyen, Maggie Chan, Jiayi Zheng, and Steven P. Dow. 2019. The civic data deluge: Understanding the challenges of analyzing large-scale community input. In Proceedings of the 2019 Designing Interactive Systems Conference (DIS'19) (June 23-28, 2019, San Diego, California). ACM, New York, 1171-1181.

[79] Andrew May and Tracy Ross. 2018. The design of civic technology: Factors that influence public participation and impact. Ergonomics 61, 2 (2018), 214-225.

[80] Brian McInnis, Xiaotong (Tone) Xu, and Steven P. Dow. 2018. How features of a civic design competition influences the collective understanding of a problem. In Proceedings of the ACM on Human-Computer Interaction 2, CSCW, Article 120 (2018), 25 pages. https: //dl.acm.org/doi/abs/10.1145/3274389.

[81] Ines Mergel. 2015. Opening government: Designing open innovation processes to collaborate with external problem solvers. Social Science Computer Review 33, 5 (2015), 599-612.

[82] Ines Mergel and Kevin C. Desouza. 2013. Implementing open innovation in the public sector: The case of challenge.gov. Public Administration Review 73, 6 (2013), 882-890.

[83] Ines Mergel, Charlies M. Schweik, and Jane E. Fountain. 2009. The transformational effect of web 2.0 technologies on government. Available at SSRN: http://doi.org/10.2139/ssrn.1412796

[84] Aditi Misra, Aaron Gooze, Kari Watkins, Mariam Asad, and Christopher A. Le Dantec. 2014. Crowdsourcing and its application to transportation data collection and management. Transportation Research Record 2414, 1 (2014), 1-8.

[85] Paul Murty, Mercedes Paulini, and Mary Lou Maher. 2010. Collective intelligence and design thinking. In Proceedings of the Design Thinking Research Symposium (DTRS'10), 309-315.

[86] S. Nambisan and P. Nambisan. 2013. Engaging Citizens in Co-creation in Public Service. IBM Center for The Business of Government, Washington, D.C.

[87] Taewoo Nam. 2012. Suggesting frameworks of citizen-sourcing via government 2.0. Government Information Quarterly 29, 1 (2012), $12-20$.

[88] Don Norman. 2013. The Design of Everyday Things. Basic Books, New York.

[89] Donald A. Norman and Pieter Jan Stappers. 2015. DesignX: Complex sociotechnical systems. She fi: The fournal of Design, Economics, and Innovation 1, 2 (2015), 83-106.

[90] Beth Simone Noveck. 2015. Smart Citizens, Smarter State: The Technologies of Expertise and the Future of Governing. Harvard University Press, Cambridge, MA.

[91] Patrick Olivier and Peter Wright. 2015. Digital civics: Taking a local turn. Interactions 22, 4 (2015), 61-63.

[92] Horst W. J. Rittel and Melvin M. Webber. 1973. Dilemmas in a general theory of planning. Policy Sciences 4, 2 (1973), 155-169.

[93] Flora Salim and Usman Haque. 2015. Urban computing in the wild: A survey on large scale participation and citizen engagement with ubiquitous computing, cyber physical systems, and Internet of Things. International fournal of Human-Computer Studies 81, 31-48.

[94] Hans J. Scholl. 2020. Digital government: Looking back and ahead on a fascinating domain of research and practice. Digital Government: Research and Practice 1, 1 (2020), 1-12.

[95] Donald A. Schon. 1984. The Reflective Practitioner: How Professionals Think in Action. Basic Books, New York.

[96] Douglas Schuler. 2020. Can technology support democracy? Digital Government: Research and Practice 1, 1 (2020), 1-14.

[97] Douglas Schuler and Aki Namioka. 1993. Participatory Design: Principles and Practices. L. Erlbaum Associates, Hillsdale, N.J.

[98] Ethan Seltzer and Dillon Mahmoudi. 2013. Citizen participation, open innovation, and crowdsourcing: Challenges and opportunities for planning. Journal of Planning Literature 28, 1 (2013), 318.

[99] Minxin Shen, Gwo-Hshiung Tzeng, and Duen-Ren Liu. 2003. Multi-criteria task assignment in workflow management systems. In Proceedings of the 36th Annual Hawaii International Conference on System Sciences (January 6-9, 2003, Big Island, Hawaii). IEEE, New York, 9 pages.

[100] Pao Siangliulue, Kenneth C. Arnold, Krzysztof Z. Gajos, and Steven P. Dow. 2015. Toward collaborative ideation at scale: Leveraging ideas from others to generate more creative and diverse ideas. In Proceedings of the 18th ACM Conference on Computer Supported Cooperative Work \& Social Computing (CSCW'15) (March 14-18, 2015, Vancouver, Canada). ACM, New York, 937-945.

[101] Herbert A. Simon. 1969. The Sciences of the Artificial. The MIT Press, Cambridge, MA.

[102] Stanford d. school. 2010. Design Thinking Bootcamp Bootleg. Stanford University, Stanford, CA.

[103] Susan Leigh Star and Karen Ruhleder. 1996. Steps toward an ecology of infrastructure: Design and access for large information spaces. Information Technology and Organizational Transformation: History, Rhetoric, and Practice, 305-346. 
[104] James Surowiecki. 2005. The Wisdom of Crowds. Anchor Books, New York.

[105] Lars Hasselblad Torres. 2007. Citizen sourcing in the public interest. Knowledge Management for Development fournal 3, 1 (2007), 134-145.

[106] Melissa A. Valentine, Daniela Retelny, Alexandra To, Negar Rahmati, Tulsee Doshi, and Michael S. Bernstein. 2017. Flash organizations: Crowdsourcing complex work by structuring crowds as organizations. In Proceedings of the 2017 CHI Conference on Human Factors in Computing Systems (CHI'17) (May 6-11, 2017, Denver, Colorado). ACM, New York, NY, 3523-3537.

[107] Vasilis Vlachokyriakos, Rob Comber, Karim Ladha, Nick Taylor, Paul Dunphy, Patrick McCorry, and Patrick Olivier. 2014. PosterVote: Expanding the action repertoire for local political activism. In Proceedings of the 2014 Conference on Designing Interactive Systems (DIS'14) (June 21-25, 2014, Vancouver, B. C., Canada. ACM, New York, 795-804.

[108] Vasillis Vlachokyriakos, Clara Crivellaro, Christopher A. Le Dantec, Eric Gordon, Pete Wright, and Patrick Olivier. 2016. Digital civics: Citizen empowerment with and through technology. In Proceedings of the 2016 CHI Conference Extended Abstracts on Human Factors in Computing Systems (CHI'16) (May 7-12, 2016, San Jose, California). ACM Inc., New York, 1096-1099.

[109] Vasillis Vlachokyriakos, Clara Crivellaro, Pete Wright, and Patrick Olivier. 2018. Infrastructuring the solidarity economy: Unpacking strategies and tactics in designing social innovation. In Proceedings of the 2018 CHI Conference on Human Factors in Computing Systems (CHI'18) (April 21-26, 2018, Montreal, Ont., Canada). ACM, New York, 1-12.

[110] Amy Voida, Lynn Dombrowski, Gillian R. Hayes, and Melissa Mazmanian. 2014. Shared values/conflicting logics: Working around e-government systems. In Proceedings of the SIGCHI Conference on Human Factors in Computing Systems (CHI'14) (April 26 - May 1 , 2014, Toronto, Ont., Canada). ACM, New York, 3583-3592.

[111] William H. Voorberg, Victor J. J. M. Bekkers, and Lars G. Tummers. 2015. A systematic review of co-creation and co-production: Embarking on the social innovation journey. Public Management Review 17, 9 (2015), 1333-1357.

[112] Linlin You, Gianmario Motta, Kaixu Liu, and Tianyi Ma. 2016. CITY FEED: A pilot system of citizen-sourcing for city issue management. ACM Transactions on Intelligent Systems and Technology (TIST) 7, 4 (2016), 53.

[113] Haiyi Zhu, Steven P. Dow, Robert E. Kraut, and Aniket Kittur. 2014. Reviewing versus doing: Learning and performance in crowd assessment. In Proceedings of the 17th ACM Conference on Computer-Supported Cooperative Work \& Social Computing (CSCW'14)(February 15-19, 2014, Baltimore, Maryland). ACM, New York, 1445-1455.

[114] FixMyStreet. Retrieved from https://www.fixmystreet.com/.

Received November 2020; revised September 2021; accepted September 2021

Digital Government: Research and Practice, Vol. 2, No. 4, Article 31. Publication date: December 2021. 